\title{
Analisis Implementasi Patient Safety Terkait Peningkatan Mutu Pelayanan Kesehatan di Rumah Sakit
}

\author{
Sumarni \\ Universitas Alma Ata Yogyakarta \\ Jalan Ringroad Barat Daya No.1, Tamantirto, Yogyakarta, Indonesia \\ Email: arniandigali@gmail.com
}

\begin{abstract}
Abstrak
Departemen Kesehatan Republik Indonesia menetapkan lima isu penting terkait keselamatan di rumah sakit, yaitu patient safety, keselamatan pekerja, keselamatan bangunan dan peralatan di rumah sakit yang bisa berdampak terhadap patient safety dan petugas, keselamatan lingkungan yang berdampak terhadap pencemaran lingkungan dan keselamatan bisnis rumah sakit yang terkait dengan kelangsungan hidup Rumah sakit. Manajemen patient safety memegang peranan sangat penting dalam peningkatan mutu pelayanan kesehatan. Patient safety merupakan upaya-upaya pelayanan yang mengutamakan keselamatan pasien. Tujuan penelitian ini untuk mengetahui implementasi patient safety terkait peningkatan mutu pelayanan kesehatan. Penelitian dilaksanakan di Rumah Sakit Ibnu Sina. Jenis penelitian yang digunakan adalah cross sectional study. Responden penelitian yaitu seluruh petugas di bidang pelayanan medik dan pelayanan penunjang di Rumah Sakit Ibnu Sina. Pengambilan sampel menggunakan teknik cluster random sampling dengan populasi 402 responden yang dijadikan sampel sebanyak 304 responden. Hasil penelitian menunjukkan bahwa tidak ada responden (0\%) yang implementasi patient safety-nya tergolong sangat lemah. Persentasi responden dengan implementasi patient safety sangat kuat, kuat, sedang dan lemah adalah sebesar 12, 25\% (30 responden), 71,57\% (224 responden), 15,69\% (39 responden) dan 0,49\% (11 responden). Berdasarkan hasil tersebut diketahui bahwa sebagian besar responden yakni 71,57\% (224 responden) berada dalam kategori implementasi patient safety yang tergolong kuat. Dimensi implementasi patient safety di Rumah Sakit Ibnu Sina tergolong tinggi dengan dimensi tertinggi pada dimensi kerjasama dalam unit sebesar 97,10\%. Berdasarkan hasil penelitian dapat disimpulkan bahwa implementasi patient safety Rumah Sakit Ibnu Sina tergolong kuat. Instalasi yang megimplementasikan patient safety yang sangat kuat adalah instalasi farmasi, sedangkan instalasi yang mengimplementasikan patient safety sedang adalah Ambulance dan Evakuator. Dimensi implementasi patient safety di Rumah Sakit Ibnu Sina tergolong tinggi dengan dimensi tertinggi terdapat pada dimensi kerjasama dalam unit, sedangkan dimensi dukungan manajemen terhadap patient safety, staffing, dan keseluruhan persepsi patient safety tergolong sedang.
\end{abstract}

Kata Kunci: implementasi patient safety, mutu pelayanan kesehatan

\section{Analysis Implementation of Patient Safety Related Enhancement Quality of Health Care in Hospital}

\begin{abstract}
Ministry of Health of the Republic of Indonesia to set out five key issues related to safety in the hospital, that patient safety, worker safety, the safety of buildings and equipment in hospitals that could have an impact on patient safety and personnel, safety of the environment that have an impact on environmental pollution and safety business Hospitals related to the survival of the Hospital. Patient safety Management plays an important role in improving the quality of health services. Patient safety is an effort that prioritizes safety services pasien. This study was to examine the implementation of Patient safety related to improving the quality of health services. The research was conducted at Ibn Sina Hospital, the type of research is cross sectional study. The respondents are all officers in the field of medical care and support services at Ibn Sina Hospital. The sampling technique used is random cluster sampling technique with a population of 402 respondents who used a sample of 304 respondents. The results showed that none of the respondents (0\%) that the implementation of patient
\end{abstract}


safety classified as very weak. The percentage of respondents to the implementation of patient safety is very strong, strong, moderate and weak amounted to $12.25 \%$ (30 respondents), $71.57 \%$ (224 respondents), $15.69 \%$ (39 respondents) and $0.49 \%$ (11 respondents). Based on these results it is known that most respondents ie $71.57 \%$ (224 respondents) is in the implementation of patient safety category classified kuatt. Based on the dimensions of most of the dimensions Implementation of Patient safety at Ibn Sina Hospital is high with the highest dimension on the dimension of cooperation in the unit amounted to $97.10 \%$. Based on the results it can be concluded that the implementation of the Patient safety Ibn Sina Hospital relatively strong. Patient safety Installation megimplementasikan very strong there in the pharmacy, while implementing patient safety installations were found on the Ambulance and Evakuator. In addition, based on the dimensions of most of the dimensions of the implementation of patient safety at Ibn Sina Hospital is high with the highest dimension on the dimension of cooperation contained in the unit, while the dimensions of the patient safety management support, staffing, patient safety and the overall perception moderate.

Keywords: implementation of patient safety, quality of health services

Info Artikel:

Artikel dikirim pada 22 Maret 2017

Artikel direvisi pada 08 Mei 2017

Artikel diterima pada 14 September 2017

DOI : http://dx.doi.org/10.21927/jnki.2017.5(2).91-99

\section{PENDAHULUAN}

Rumah sakit sebagai instansi pelayanan kesehatan yang berhubungan langsung dengan pasien harus mengutamakan pelayanan kesehatan yang aman, bermutu, antidiskriminasi dan efektif dengan mengutamakan kepentingan pasien sesuai dengan standar pelayanan rumah sakit (1). Pasien sebagai pengguna pelayanan kesehatan berhak memperoleh keamanan dan keselamatan dirinya selama dalam perawatan di rumah sakit (2). Perkembangan rumah sakit saat ini telah mengalami transformasi. Industri rumah sakit mengalami perkembangan cukup pesat seiring diterbitkannya berbagai peraturan dan perundang-undangan yang mendukung iklim investasi dan menciptakan kondisi bisnis dan jasa rumah sakit yang lebih baik. Aktifnya para pelaku bisnis dalam berinvestasi di industri rumah sakit di tanah air seiring sejalan dengan upaya pemerintah menyediakan jasa layanan kesehatan kepada masyarakat. Berdasarkan profil kesehatan dari tahun 2013 sampai dengan tahun 2015 Peningkatan jumlah rumah sakit mengalami peningkatan yang sangat besar dengan angka mencapai 2.488 dengan kepemilikan yang beragam. Hal tersebut menunjukkan meningkatnya kebutuhan masyarakat akan layanan jasa kesehatan. Dengan demikian setiap rumah sakit dituntut untuk meningkatkan mutu layanan dalam memenuhi kebutuhan masyarakat tersebut. Agar Rumah Sakit dapat mencapai tujuannya, maka fungsi koordinasi memegang peranan penting dalam prosesnya, sehingga mampu menciptakan kualitas pelayanan yang optimal bagi para pasien. Kepuasan pasien dalam hal ini dapat terpenuhi apabila penyelenggaraan pelayanan memperhatikan beberapa asas, yakni pelayanan medik, petugas pelayanan dan biaya pelayanan (3).

Isu penting terkait keselamatan di rumah sakit (RS) yaitu: keselamatan pasien, keselamatan pekerja atau petugas kesehatan, keselamatan bangunan dan peralatan di RS yang berdampak terhadap keselamatan pasien dan petugas, keselamatan lingkungan yang berdampak terhadap pencemaran lingkungan, dan keselamatan "bisnis" RS terkait dengan kelangsungan hidup RS (4). Patient safety merupakan istilah yang saat ini cukup populer dalam pelayanan kesehatan. Patient safety merupakan upaya-upaya pelayanan yang mengutamakan pada keselamatan pasien. Keselamatan pasien (patient safety) adalah suatu sistem dimana rumah sakit membuat asuhan pasien lebih aman, mencegah terjadinya cidera yang disebabkan oleh kesalahan akibat melaksanakan suatu tindakan atau tidak mengambil tindakan yang seharusnya diambil. Sistem tersebut meliputi pengenalan resiko, identifikasi dan pengelolaan hal yang berhubungan dengan resiko pasien, pelaporan dan analisis insiden, kemampuan belajar dari insiden, tindak lanjut dan implementasi solusi untuk meminimalkan resiko (5).

Data yang dirilis oleh Health and Human Service (HHS) menunjukkan bahwa sepanjang 2010- 
2014 di Amerika telah terjadi penurunan kejadian terkait patient safety di rumah sakit sebesar $17 \%$. Hal ini telah memberi kontribusi utama terhadap menurunnya kematian pasien (akibat kejadian tidak diinginkan) sebanyak 87 ribu kasus. Zero patient harm merupakan langkah yang baik bagi pelayanan kesehatan di Amerika. Dimana ada tantangan lain bagi patient safety seperti medical errors yang terjadi di tahun 2015, yang merupakan satu dari berbagai error yang paling banyak terjadi, dimana setiap tahun setidaknya ada $5 \%$ pasien rawat inap yang mengalami kejadian tak diinginkan terkait dengan pemberian obat. Ini tidak hanya terjadi pada pasien rawat inap, tapi juga pada pasien yang sedang menjalani dioperasi. Dibulan oktober sendiri separuh dari operasi mengalami medication errors, seperti pemberian dosis tidak tepat, mengabaikan tindakan yang harus dilakukan berdasarkan tanda vital pada pasien, kesalahan dalam pelabelan serta documentation errors yang dilansir dalam sebuah studi di Massachusetts General Hospital. Laporan penelitian yang dilakukan oleh Institute of Medicine mengungkapkan adanya Diagnostic errors terkait Improving Diagnosis in Health Care. Berdasarkan laporan tersebut data yang ada menunjukkan 10\% kematian pasien disebabkan oleh diagnostic error yang disebabkan oleh kejadian tidak diinginkan dengan persentase $6 \%$. Diagnostic error menjadi salah satu isu yang mendapat perhatian khusus karena hal ini merupakan penyebab tingginya error dan bahkan kematian pasien. Untuk menghindari kejadian tersebut diharapkan adanya kerjasama oleh semua stakeholder pelayanan kesehatan serta membangun komunikasi dan mitra yang baik dengan pasien dan keluarganya. Adapun di Indonesia tingkat KTD sebagaimana laporan insiden patient safety tahun 2007 sebesar 46,2\% dan pada tahun 2010 sebesar 63\% (6). Publikasi WHO (World Health Organization), melaporkan insiden keselamatan pasien bahwa kesalahan medis terjadi pada $8 \%$ sampai $12 \%$ dari ruang rawat inap. Sementara $23 \%$ dari warga Uni Eropa 18\% mengaku telah mengalami kesalahan medis yang serius di rumah sakit dan $11 \%$ telah diresepkan obat yang salah. Bukti kesalahan medis menunjukkan bahwa $50 \%$ sampai $70,2 \%$ dari kerusakan tersebut dapat dicegah melalui pendekatan yang sistematis komprehensif untuk keselamatan pasien (7).

Berdasarkan UU No.1691/MENKES/PER/ VIII/2011 tentang patient safety pihak rumah sakit diharuskan melakukan kegiatan pelayanan dengan lebih mengutamakan patient safety (8). Kurangnya kesadaran dan kepedulian akan pentingnya patient safety akan mengakibatkan kerugian bagi pihak rumah sakit dan juga pasien seperti bertambah lamanya pasien dirawat yang akan berdampak pada semakin besarnya biaya yang harus ditanggung dan terjadinya resistensi obat (9). Analisis AHRQ berdasarkan pelatihan menemukan sebesar $55 \%$ akar masalah terkait jumlah KTD Sebanyak 2.966 masalah. Mencegah dampak pasien terhadap KTD terkait kematian dan ketidakmampuan yang menetap sangat erat kaitannya dengan kinerja perawat dalam lingkup penerapan patient safety (10). Considine mengatakan bahwa untuk mencegah KTD beserta dampaknya yaitu dengan peningkatan kemampuan perawat terkait pencegahan dini, deteksi risiko serta koreksi terhadap abnormalitas yang mungkin bisa terjadi pada pasien (11). Schoonhoven, Grobbee, Bousema dan Buskens berpendapat bahwa ketidakseragaman persepsi terkait deteksi risiki terhadap pasien akan mengakibatkan pressure ulcer berdasarkan temuan data sebesar $70 \%$ (12). Dengan demikian KTD dapat diturunkan dengan penerapan patient safety yang baik. Upaya untuk membangun budaya keselamatan pasien (culture of safety) disokong oleh tiga plar yaitu teknologi, proses, dan SDM sebagai pilar dari pondasi perawatan pasien secara aman (13).

Program keselamatan pasien mulai dari perencanaan hingga evaluasi menjadi wewenang tim keselamatan pasien rumah sakit. Berdasarkan data yang diambil dari bagian KPRS dalam rentang tahun 2009-2014 didaptkan jumlah kasus 29. Dengan rincian, yaitu kejadian pada tahun 2009, kasus pada tahun 2010, kasus pada tahun 2011, kasuas pada tahun 2012, kasus pada tahun 2013, dan kasus pada tahun 2014. Laporan kinerja Rumah Sakit Ibnu Sina Tahun 2016 triwulan II terdapat kejadian pasien jatuh sebanyak 8 orang meskipun tidak mengakibatkan cacat atau meninggal. Hal tersebut menunjukkan capaian indikator tidak adanya pasien jatuh sebesar $58,79 \%$ yang tidak mencapai standar pelayanan minimal No. 129/Menkes/SK/II/2008 yang seharusnya 100 . Selain itu, Rumah Sakit Ibnu Sina belum memiliki ruang isolasi yang terstandar, sehingga berpotensi terjadinya infeksi silang antar pasien. Hal tersebut dikarenakan banyak rumah sakit yang mengaplikasikan sistem keselamatan yang baik, tetapi pada kenyataannya KTD tetap terjadi. Meskipun pada umumnya jika sistem dapat 
dijalankan sebagaimana mestinya maka KTD dapat ditekan sekecil-kecilnya, namun fakta menunjukkan bahwa sistem tidak dapat berjalan secara optimal jika kompetensi dan nilai-nilai atau Implementasi yang ada tidak mendukung (14).

Di Indonesia berdasarkan data insiden keselamatan pasien yang diterbitkan KKPRS (Komite Keselamatan Pasien Rumah sakit) terdapat 114 laporan insiden keselamatan pasien pada tahun 2009, 103 laporan pada tahun 2010, dan 34 laporan di tahun 2011 pada tri wulan I (15). Terjadinya insiden keselamatan pasien di suatu rumah sakit akan memberikan dampak yang merugikan bagi pihak rumah sakit, staf, dan pasien sebagai penerima pelayanan berpendapat bahwa hal buruk yang ditimbulkan adalah menurunnya tingkat kepercayaan pasien terhadap pelayanan kesehatan (16). Hasil penelitian Dwiyanto dengan judul "penerapan hospital by laws dalam meningkatkan patient safety di Rumah sakit" mengungkapkan bahwa tujuan utama dari keselamatan pasien adalah mencegah terjadinya cidera yang diakibatkan oleh kesalahan akibat melaksanakan suatu tindakan atau tidak melaksanakan tindakan yang seharusnya diambil (17). Hal tersebut dapat dicapai dengan peningkatan kualitas mutu pelayanan medis yang dilakukan oleh seluruh staf di rumah sakit. Peningkatan kualitas pelayanan agar lebih efektif dan efisien dapat dilakukan dengan pelaksanaan audit medis di rumah sakit.

Mutu pelayanan yang berkualias dan dibarengi dengan jaminan patient safety yang tinggi akan menghasilkan citra rumah sakit yang baik dimata pasien sebagai konsumen rumah sakit. Nilai patient safety merupakan hal yang sangat penting untuk diterapkan dan ditanamkan pada setiap anggota organisasi, karena patient safety merupakan hal yang fundamental. Pemahaman yang baik terkait patient safety akan menjadikan setiap anggota organisasi mengetahui apa yang akan dilakukan. Perilaku tersebut pada akhirnya menjadi suatu implementasi yang tertanam dalam setiap anggota organisasi berupa perilaku Implementasi patient safety. Tujuan penelitian adalah untuk menganalisis pengaruh implementasi patient safety terhadap penigkatan mutu pelayanan kesehatan. Dengan tujuan khususnya untuk menganalisis implementasi patient safety pada Instalasi Rawat Darurat, Instalasi Rawat Jalan, Instalasi Rawat Inap, HCU dan ICU, Instalasi Kamar Operasi, Kemotherapi, Kemotherapi,
Instalasi Radiologi, Instalasi Laboratorium, Instalasi Farmasi, Instalasi Gizi, Instalasi CSSD \& Laundry, Instalasi Pemeliharaan Sarana Medis dan Ambulance dan Evakuator di Rumah Sakit Ibnu Sina.

\section{BAHAN DAN METODE}

Jenis penelitian yang digunakan dalam penelitian ini adalah cross sectional study yaitu suatu rancangan yang mengkaji dinamika korelasi antara variabel independen (patient safety) dan variabel dependen (peningkatan mutu pelayanan kesehatan) pada saat bersamaan (point penelitian analitik time approach) (18).

Populasi dalam penelitian ini adalah seluruh petugas di bidang pelayanan medik dan penunjang dengan jumlah keseluruhan populasi adalah 402 responden. Penelitian ini dilaksanakan di Rumah Sakit Ibnu Sina. Waktu pelaksanaan yaitu pada bulan Maret-Mei 2016. Jumlah sampel penelitian adalah 304 responden, dimana pengambilan sampel pada setiap subpopulasi menggunakan teknik cluster random sampling. Sumber data dalam penelitian ini berupa data primer dan sekunder. Data primer diperoleh dari kuesioner yang dibagikan kepada seluruh responden lengkap dengan jawabannya. Sedangkan data sekunder diperoleh langsung dari dokumendokumen rumah sakit yang terkait dan mendukung untuk penelitian ini. Alat pengumpulan data dalam penelitian ini adalah kuesioner implementasi patient safety diadopsi dari kuesioner Hospital Survey on Patient safety Culture dipublikasikan oleh The Agency for Healthcare Research and Quality tahun 2004 (19). Analisis data dilakukan dalam tiga bagian yaitu analisis univariat, bivariat dan multivariat. Analisis univariat merupakan analisis sebaran persentase variabel tunggal yang termasuk karakteristik umum responden yang disajikan dalam bentuk tabel distribusi frekuensi.

\section{HASIL DAN BAHASAN}

\section{Analisis Implementasi Patient Safety di Rumah Sakit Ibnu Sina}

Distribusi frekuensi kategorisasi implementasi patient safety di Rumah Sakit Ibnu Sina digolongkan menjadi sangat lemah, lemah, sedang, kuat, dan sangat kuat disajikan dalam Tabel 1.

Berdasarkan Tabel 1 Persentasi responden yang memiliki implementasi patient safety sangat 
Tabel 1. Distribusi Frekuensi Kategorisasi Implementasi Patient Safety di Rumah Sakit Ibnu Sina Tahun 2016

\begin{tabular}{lcc}
\hline Implementasi Patient Safety & $\mathbf{f}$ & $\mathbf{\%}$ \\
\hline Lemah & 11 & 0,49 \\
Sedang & 39 & 15,69 \\
Kuat & 224 & 71,57 \\
Sangat kuat & 30 & 12,25 \\
\hline
\end{tabular}

Sumber: Data Primer Tahun 2016

kuat, kuat, sedang dan lemah adalah sebesar 12,25\% (30 responden), 71,57\% (224 responden), $15,69 \%$ (39 responden) dan 0,49\% (11 responden). Berdasarkan hasil tersebut diketahui bahwa sebagian besar responden yakni $71,57 \%$ (224 responden), berada dalam kategori implementasi patient safety yang tergolong kuat, sehingga dapat disimpulkan bahwa implementasi patient safety pada Rumah Sakit Ibnu Sina tergolong kuat.

Semakin tinggi keselamatan pasien maka semakin baik mutu suatu rumah sakit, ketika pasien terkena insiden maka akan beralih ke rumah sakit lain, patient safety dan mutu rumah sakit berkorelasi positif. Responden juga menyatakan bahwa pasien yang mendapatkan pelayanan yang aman di rumah sakit akan mengdongkrak customer feeding, ketidak puasan pasien akan sangat berpengaruh pada kualitas atau mutu. Hal ini juga sesuai dengan teori Mukti yang menyatakan, bahwa pelayanan bermutu diartikan sejauh mana realitas pelayanan kesehatan yang diberikan sesuai dengan kriteria, standar profesional medis terkini, baik yang telah memenuhi atau melebihi kebutuhan dan keinginan pelanggan dengan tingkat efisiensi yang optimal (20). Membangun kualitas dimulai dari kebutuhan atau keinginan pelanggan dan berakhir pada persepsi pelanggan. Semakin meningkatnya manajemen patient safety yang terwujud dalam menurunnya tingkat insiden maka dapat dikatakan semakin baik pula mutu pelayanan di instansi pelayanan kesehatan.

Dukungan manajemen dan direktur Rumah Sakit Ibnu Sina dalam meningkatkan implementasi patient safety dapat dilihat dari dibentuknya komite hospital safety, diadakannya pelatihan-pelatihan yang berkaitan dengan patient safety, serta adanya penataan sistem keselamatan dan standar opersional pelayanan yang sesuai prosedur patient safety, ditambah dengan adanya pengawasan dari pimpinan Rumah Sakit Ibnu Sina sangat dirasakan petugas memberikan kontribusi bagi terciptanya implementasi patient safety di Rumah Sakit Ibnu Sina. Adapun pada setiap instalasi, implementasi patient safety dominan tinggi. Akan tetapi pada Instalasi radiologi implementasi patient safety tergolong sangat tinggi sedangkan instalasi Ambulance dan Evakuator implementasi patient safety tergolong sedang.

Implementasi patient safety yang tinggi pada instalasi radiologi disebabkan karena adanya kerjasama yang baik dalam unit dan antar unit dalam peningkatan patient safety yang dirasakan petugas Instalasi radiologi. Hal tersebut sejalan dengan penelitian Rachmawati yang menunjukan bahwa kerjasama tim berpengaruh positif dan signifikan terhadap Implementasi patient safety (21). Adapun implementasi patient safety yang tergolong sedang pada ambulance dan evakuator dikarenakan kurangnya pelatihan tentang patient safety yang didapatkan petugas ambulance dan evakuator. Pelatihan merupakan metode yang terorganisir untuk memastikan bahwa individu memiliki pengetahuan dan keterampilan tertentu dalam mengerjakan kewajiban dan tanggung jawab pekerjaan yang lebih baik (22).

Implementasi patient safety merupakan suatu hal yang penting karena implementasi patient safety adalah suatu cara untuk membangun program patient safety secara keseluruhan, karena jika kita lebih fokus pada implementasi patient safety maka akan lebih menghasilkan hasil keselamatan yang lebih apabila dibandingkan hanya berfokus pada program patient safety saja (9). Membangun kesadaran akan nilai patient safety, memimpin dan mendukung staf dalam penerapan patient safety merupakan bagian penting dalam menciptakan budaya patient safety (PMK No. 1691 Tahun 2011). Sejalan dengan itu, Rachmawati mengemukakan bahwa faktor-faktor yang mempengaruhi implementasi keselamatan pasien diantaranya dapat dilihat dari tingkat manajemen dan tingkat organisasi (21). Tingkat manajemen meliputi persepsi manajemen tentang patient safety dan keterlibatan manajemen dalam patient safety, sedangkan tingkat organisasi meliputi kepemimpinan transformasional, SDM, kepemimpinan komite keselamatan pasien, kepemimpinan pengawas safety, kejelasan dan keteraturan penempatan kerja dan audit proses.

Implementasi Patient Safety di Rumah Sakit Ibnu Sina disetiap instalasi tergolong kuat ini dapat dilihat dengan adanya persentase dari implementasi patient safety yang tergolong tinggi yaitu $72,7 \%$ dapat dilihat di Tabel 2. 
Tabel 2. Distribusi Implementasi Patient safety pada Setiap Instalasi di Rumah Sakit Ibnu Sina Tahun 2016

\begin{tabular}{|c|c|c|c|c|c|c|c|c|c|c|}
\hline \multirow{3}{*}{ Intalasi } & \multicolumn{8}{|c|}{ Implementasi Patient safety } & \multirow{2}{*}{\multicolumn{2}{|c|}{ Total }} \\
\hline & \multicolumn{2}{|c|}{ Lemah } & \multicolumn{2}{|c|}{ Sedang } & \multicolumn{2}{|c|}{ Kuat } & \multicolumn{2}{|c|}{ Sangat Kuat } & & \\
\hline & $\mathbf{n}$ & $\%$ & $\mathbf{n}$ & $\%$ & $\mathbf{n}$ & $\%$ & $\mathrm{n}$ & $\%$ & $\mathbf{n}$ & $\%$ \\
\hline Instalasi Rawat Darurat & 0 & 0 & 5 & 33,3 & 30 & 66,7 & 0 & 0 & 35 & 100 \\
\hline Instalasi Rawat Jalan & 0 & 0 & 3 & 16,7 & 15 & 61,7 & 4 & 22,2 & 22 & 100 \\
\hline Instalasi Rawat Inap & 0 & 0 & 9 & 16,4 & 44 & 72,7 & 6 & 10,9 & 59 & 100 \\
\hline HCU \& ICU & 0 & 0 & 0 & 0 & 18 & 92,9 & 2 & 7,1 & 20 & 100 \\
\hline Instalasi Kamar Operasi & 0 & 0 & 3 & 16,7 & 13 & 83,3 & 0 & 0 & 16 & 100 \\
\hline Instalasi Radiologi & 0 & 0 & 4 & 10,0 & 0 & 0 & 12 & 90,0 & 16 & 100 \\
\hline Intalasi Rekam Medik & 0 & 0 & 2 & 28,6 & 7 & 71,4 & 0 & 0 & 9 & 100 \\
\hline Kemotherapi & 0 & 0 & 0 & 0 & 9 & 71,4 & 2 & 28,6 & 11 & 100 \\
\hline Instalasi Laboratorium & 0 & 0 & 2 & 8,3 & 13 & 75 & 7 & 16,7 & 22 & 100 \\
\hline Instalasi Gizi & 0 & 0 & 0 & 0 & 20 & 83,3 & 6 & 16,7 & 26 & 100 \\
\hline Instalasi Farmasi & 0 & 0 & 9 & 42,1 & 17 & 52,1 & 2 & 5,3 & 28 & 100 \\
\hline Instalasi CSSD \& Laundry & 0 & 0 & 1 & 12,5 & 12 & 75 & 1 & 12,5 & 14 & 100 \\
\hline $\begin{array}{l}\text { Instalasi Pemeliharaan Sarana Medis } \\
\text { Rumah sakit (IPSRS) }\end{array}$ & 0 & 0 & 2 & 11,8 & 10 & 70,6 & 3 & 17,6 & 15 & 100 \\
\hline Ambulance \& Evakuator & 1 & 9,1 & 10 & 90,9 & 0 & 0 & 0 & 0 & 11 & 100 \\
\hline Total & 1 & 0,49 & 50 & 21,59 & 208 & 66,67 & 45 & 11,25 & 304 & 100 \\
\hline
\end{tabular}

Sumber: Data Primer Tahun 2016

Berdasarkan Tabel 2 menunjukkan bahwa hampir semua instalasi berada dalam kategori implementasi patient safety yang tergolong kuat. Namun jika dilihat berdasarkan persentasi maka Kemoterapi memiliki persentasi terbesar yaitu 100\% dengan kategorisasi sangat kuat. Selain itu jika dilihat berdasarkan jumlah responden maka instalasi rawat inap memiliki jumlah responden terbesar yaitu 44 responden $(72,7 \%)$ disusul instalasi rawat darurat memiliki jumlah responden yaitu 33,3 responden $(66,7 \%)$ dengan kategorisasi kuat. Adapun pada instalasi farmasi responden berada dalam kategori sedang bergerak ke kuat dengan persentasi $42,1 \%$ ke $52,1 \%$. Dengan demikian dapat disimpulkan bahwa Implementasi patient safety di setiap instalasi pada Rumah Sakit Ibnu Sina tergolong kuat.

\section{Deskripsi Implementasi Patient SafetyBerdasarkan Dimensi di Rumah Sakit Ibnu Sina}

Peningkatan mutu dan keselamatan pasien saling berhubungan, Semakin tinggi keselamatan pasien maka semakin baik mutu suatu rumah sakit, ketika pasien terkena insiden maka akan beralih ke rumah sakit lain, patient safety dan mutu rumah sakit berkorelasi positif. Untuk implemetasi patien safety berdasarkan dimensi dapat dilihat pada Tabel 3.

Berdasarkan Tabel 3 menunjukan bahwa hampir semua dimensi respondennya berada dalam kategori tinggi. Dimensi yang respondennya berada pada kategori tinggi dengan persentasi terbesar yaitu
97,10\% (294 responden) terdapat pada dimensi kerjasama dalam unit. Selain itu keseluruhan persepsi tentang patient safety respondennya berada dalam kategori sedang dengan persentasi berturut-turut sebesar $65,72 \%$ (165 responden), 96,47\% (207 responden), dan 76,14\% (206 responden). Dengan demikian dapat disimpulkan bahwa jumlah responden berada dalam kategori tinggi pada hampir semua dimensi dengan dimensi tertinggi terdapat pada dimensi kerjasama dalam unit, sedangkan dimensi dukungan manajemen terhadap patient safety, staffing, dan keseluruhan persepsi tentang patient safety tergolong sedang.

Stephen dan Timothy menyatakan kerjasama tim adalah kelompok yang usaha-usaha individualnya menghasilkan kinerja lebih tinggi daripada jumlah masukan individual. Kerjasama tim menghasilkan sinergi positif melalui usaha yang terkoordinasi (23). Hal ini memiliki pengertian bahwa kinerja yang dicapai oleh sebuah tim lebih baik daripada kinerja perindividu di suatu organisasi ataupun suatu perusahaan. Kerjasama dalam unit di Rumah Sakit Ibnu Sina yang tergolong tinggi disebabkan karena adanya rasa tanggung jawab kerja para petugas dan pengevaluasian atau pemantauan setiap program patient safety yang dilakukan pihak Rumah Sakit Ibnu Sina. Menurut Baker et all kerja tim sangat dibutuhkan diantara tim medis untuk meningkatkan patient safety melalui pengurangan kesalahan-kesalahan akibat adanya kerjasama tim antara petugas medis (24). 
Tabel 3. Distribusi Kategorisasi Implementasi Patient Safety Berdasarkan Dimensi di Rumah Sakit Ibnu Sina Tahun 2016

\begin{tabular}{|c|c|c|c|c|c|c|c|c|}
\hline \multirow{3}{*}{ Dimensi } & \multicolumn{6}{|c|}{ Kategori Jawaban Responden } & \multirow{2}{*}{\multicolumn{2}{|c|}{ Total }} \\
\hline & \multicolumn{2}{|c|}{ Rendah } & \multicolumn{2}{|c|}{ Sedang } & \multicolumn{2}{|c|}{ Tinggi } & & \\
\hline & $\mathbf{n}$ & $\%$ & $\mathbf{n}$ & $\%$ & $\mathbf{n}$ & $\%$ & $\mathbf{n}$ & $\%$ \\
\hline $\begin{array}{l}\text { Espektasi Supervisor/Manajer dan Tindakan Promosi } \\
\text { Keselamatan }\end{array}$ & 1 & 0,49 & 97 & 22,35 & 206 & 77,16 & 304 & 100 \\
\hline Pembelajaran Organisasi dan Peningkatan Berkelanjutan & 5 & 1,47 & 55 & 12,26 & 244 & 86,27 & 304 & 100 \\
\hline Kerjasama dalam Unit & 2 & 0,98 & 8 & 3,92 & 294 & 97,10 & 304 & 100 \\
\hline Keterbukaan Komunikasi & 5 & 1,47 & 81 & 25 & 218 & 73,53 & 304 & 100 \\
\hline Umpan Balik dan Komunikasi Tentang Error & 1 & 0,49 & 92 & 30,39 & 211 & 69,12 & 304 & 100 \\
\hline Dukungan Manajemen terhadap Patient Safety & 24 & 4,86 & 165 & 65,72 & 115 & 29,42 & 304 & 100 \\
\hline Staffing & 65 & 12,71 & 207 & 96,47 & 32 & 8,82 & 304 & 100 \\
\hline Respon nonpunitif terhadap Error & 0 & 0 & 99 & 38,73 & 205 & 61,27 & 304 & 100 \\
\hline Kerjasama antar Unit & 0 & 0 & 90 & 38,24 & 214 & 61,76 & 304 & 100 \\
\hline Pergantian Shift dan Perpindahan Pasien & 15 & 2,45 & 112 & 40,2 & 177 & 57,35 & 304 & 100 \\
\hline Keseluruhan Persepsi tentang Patient safety & 0 & 0 & 206 & 76,14 & 98 & 23,86 & 304 & 100 \\
\hline Frekuensi Pelaporan Kejadian & 56 & 12,75 & 74 & 36,27 & 174 & 50,98 & 304 & 100 \\
\hline
\end{tabular}

Sumber: Data Primer Tahun 2016

Adapun dimensi dukungan manajemen terhadap patient safety, staffing, dan keseluruhan persepsi terhadap patient safety yang tergolong sedang disebabkan faktor individu atau petugas itu sendiri, seperti masih kurangnya kesadaran petugas untuk melaporkan setiap insiden yang terjadi di rumah sakit. Hal tersebut ditunjukan dengan adanya implementasi menyalahkan masih ada di lingkungan rumah sakit, sehingga petugas cenderung tidak melaporkan karena takut dimarahi atau tidak mau temannya dimarahi. Petugas masih kurang memiliki kesadaran diri dalam mengaplikasikan setiap program patient safety yang dibuat pihak rumah sakit. Sejalan dengan yang dikemukakan Rachmawati bahwa faktor individu atau patugas sangat berpengaruh terhadap implementasi patient safety, dimana faktor yang berkaitan dengan indivitu berupa kesadaran diri, beban kerja, tingkat stress, tingkat kelelahan, perasaan takut disalahkan, perasaan malu, dan keterlibatan keluarga atau pasien (21).

\section{Deskripsi Dimensi Implementasi Patient Safety pada setiap Instalasi di Rumah Sakit Ibnu Sina}

Implementasi patient safety umumnya tergolong tinggi di setiap instalasi di Rumah Sakit Ibnu Sina, kecuali pada dimensi dukungan manajemen terhadap patient safety, staffing, keseluruhan persepsi tentang patient safety, dan dimensi staffing tergolong rendah pada instalasi kamar operasi begitupun dengan pelaporan kejadian masih tergolong sedang. Hal tersebut sejalan dengan penelitian Hikmah di RSUP Fatmawati yang juga menunjukan masih rendahnya dimensi respon berarti terhadap eror, staffing, keseluruhan persepsi tentang patient safety, dan frekuensi pelaporan kejadian pada petugasa instalasi rawat darurat. Keselamatan pasien menjadi prioritas pertama dalam pemberian layanan kesehatan dan layanan keperawatan di rumah sakit (25). Agnew et al menyatakan penerapan budaya keselamatan bermanifestasi sebagai iklim keselamatan dan merupakan sebuah potret dari budaya keselamatan yang berlaku dalam individu dan kelompok, serta dapat diukur dengan kuesioner (26). Keselamatan pasien juga merupakan langkah kritis pertama untuk memperbaiki kualitas pelayanan, serta berkaitan dengan mutu dan citra rumah sakit. Keselamatan pasien dipengaruhi oleh berbagi faktor yang saling berinteraksi dalam sistem kesehatan (27). Faktor yang berpengerauh terhadap sistem kesehatan dan keselamatan pasien yakni, petugas kesehatan, sifat dasar pekerjaan, lingkungan fisik, faktor penyatuan system dengan berbagai faktor organisasi atau lingkungan sosial dan faktor manajemen. Faktor manajemen meliputi ketenagaan, struktur organisasi, penjadwalan, ketersediaan sumber daya, dan komitmen terhadap kualitas. Mengenali sesuatu yang tidak baik dalam sebuah organisasi merupakan potensi aktif dari setiap anggota organisasi, hal ini dapat terlihat dengan adanya kesadaran konstan terkait budaya keselamatan pasien. Melaksanakan budaya keselamatan pasien adalah bentuk dari perbaikan kinerja oleh setiap anggota organisasi, seperti mengakui kesalahan dan mau belajar dari kesalahan tersebut serta mau mengambil tindakan 
tepat Kedisiplinan, ketaatan terhadap standar, prosedur dan protokol, bekerja dalam tim, kejujuran, keterbukaan, saling menghargai adalah nilai dasar yang harus dijunjung tinggi (28).

\section{Implementasi Patient Safety dalam Upaya Peningkatan Mutu Pelayanan di Rumah Sakit lbnu Sina}

Peningkatan mutu dan keselamatan pasien saling berhubungan, pemberian asuhan pasien sesuai kebutuhan, dokter, perawat, tenaga bedah yang berkompeten, SDM sesuai kompetensi, alat sesuai kebutuhan pasien, peralatan mendukung patient safety dapat meningkatkan mutu pelayanan. Semakin tinggi keselamatan pasien maka semakin baik mutu suatu rumah sakit, ketika pasien terkena insiden maka akan beralih ke rumah sakit lain, patient safety dan mutu rumah sakit berkorelasi positif. Peningkatan mutu pelayanan medis di rumah sakit yang dilakukan secara gotong-royong oleh tenaga medis, staff kesehatan fungsional dengan melakukan pelayanan medis yang bermutu (17). Hal ini juga sesuai dengan teori yang menyatakan bahwa pelayanan bermutu diartikan sejauh mana realitas pelayanan kesehatan yang diberikan sesuai dengan kriteria, standar profesional medis terkini, baik yang telah memenuhi atau melebihi kebutuhan dan keinginan pelanggan dengan tingkat efisiensi yang optimal (20). Sistem harus dibuat sedemikian rupa sehingga petugas mudah untuk berbuat benar dan tidak mudah membuat kesalahan melalui dukungan teknologi, kerjasama tim, komunikasi, SDM yang memenuhi syarat, supervisi, standarisasi prosedur dan lainnya (27).

Patient safety dan mutu rumah sakit saling berhubungan erat, hal ini ditunjukan berdasarkan hasil wawancara dengan responden yang mengatakan bahwa kualitas mutu rumah sakit akan mengakibatkan semakin tingginya tingkat keselamatan pasien. Responden juga mengungkapkan bahwa kualitas atau mutu sangat dipengaruhi oleh pelayanan yang berkualitas dan aman dan akan berdampak pada kepuasan pasien.

\section{SIMPULAN DAN SARAN}

Berdasarkan hasil penelitian dapat disimpulkan bahwa implementasi patient safety Rumah Sakit Ibnu Sina tergolong kuat. Implementasi patient safety pada setiap instalasi di Rumah Sakit Ibnu Sina tergolong kuat dengan instalasi yang memiliki implementasi patient safety yang sangat kuat terdapat pada instalasi farmasi, sedangkan instalasi yang mengimplementasikan patient safety yang sedang terdapat pada Ambulance dan Evakuator. Selain itu, dilihat berdasarkan dimensi maka sebagian besar dimensi implementasi patient safety di Rumah Sakit Ibnu Sina tergolong tinggi dengan dimensi tertinggi terdapat pada dimensi kerjasama dalam unit, sedangkan dimensi dukungan manajemen terhadap patient safety, staffing, dan keseluruhan persepsi tentang patient safety tergolong sedang. Adapun dimensi implementasi patient safety pada setiap instalasi di Rumah Sakit Ibnu Sina pada umumnya tergolong tinggi, kecuali pada dimensi dukungan manajemen terhadap patient safety, staffing, keseluruhan persepsi tentang patient safety, dan frekuensi pelaporan kejadian yang tergolong sedang, bahkan dimensi staffing tergolong rendah pada instalasi kamar operasi. Hal ini sejalan dengan harapan Rumah Sakit Ibnu Sina dalam membangun komitmen dan fokus yang jelas tentang patient safety adalah dengan ikut bertanggungjawabnya direksi dalam sistem manajemen patient safety, kemauan direksi dalam mencanangkan gerakan patient safety, laporan triwulan yang selalu dilaporkan kepada direksi, pembahasan langsung kepada direksi dalam kasus insiden dengan great merah dan kuning, mencari akar permasalahan dan mencari jalan keluar insiden agar tidak terulang kembali, pelatihan kepada minimal koordinator disetiap bagian tentang patient safety.

Disarankan bagi pihak rumah sakit dalam upaya mempertahankan serta terus meningkatkan implementasi patient safety yang telah ada diperlukan peningkatan kesadaran individu, pengevaluasian, pengawasan, kelengkapan peralatan dan sarana dalam menunjang penerapan program patient safety. Serta melaksanakan pertemuan rutin yang membahas mengenai patient safety yang dilakukan oleh tim dan koordinator setiap bagian.

\section{RUJUKAN}

1. Undang-Undang tentang Kesehatan dan Rumah Sakit Pasal 29b UU No.44/2009.

2. Undang-Undang tentang Kesehatan dan Rumah Sakit Pasal 32n UU No.44/2009.

3. Fandy T. Manajemen Jasa. $1^{\text {st }}$ Ed. Yogyakarta: Andi; 2006.

4. Kementerian Kesehatan RI. Rencana Strategis Kementerian Kesehatan Tahun 2010-2014. Jakarta: Kemenkes RI; 2010. 
5. Departemen Kesehatan. Utamakan Patient Safety [Internet]. 2008 [cited 2017 Apr 4]. Available from: http://majalahkasih.pantiwilasa. com/detailpost/peran-perawat-dalampenerapansasaran-keselamatan-pasien

6. Lumenta A. Pedoman Pelaporan linsiden Keselamatan Pasien IKP: Patient Safety Incident Report. $2^{\text {nd }}$ Ed. Jakarta: Komite Keselamatan Pasien Rumah Sakit KKP-RS; 2008:9-11.

7. WHO. Patient Safety [Internet]. 2016 [cited 2017 Apr 4]. Available from: www.who.int:http:// patientsafety/implementation/information_ model/e/

8. Permenkes RI No 1691/MENKES/PER/VIII/2011. Patient Safety Rumah sakit; 2014.

9. Setiowati D. Hubungan Kepemimpinan Efektif Head Nurse dengan Penerapan Budaya Patient safety oleh Perawat Pelaksana di RSUPN Dr. Cipto Mangkusumo Jakarta. [Jakarta]: Universitas Indonesia; 2010.

10. Agency for Healthcare Research and Quality (AHRQ), Publication no. 07-E005.Rockville, MD: Agency fir Healthcare Research and Quality: 151. www.ahrq.gov; 2003.

11. Considine J. The role of nurses in preventing adverse events related to respiratory dysfunction: literature review. J Adv Nurs [Internet]. 2005 Mar;49(6):624-33. Available from: http://www. ncbi.nlm.nih.gov/pubmed/15737223

12. Schoonhoven L. Prediction of pressure ulcer development in hospitalized patients: a tool for risk assessment. Qual Saf Heal Care [Internet]. 2006 Feb 1;15(1):65-70. Available from: http:// qualitysafety.bmj.com/lookup/doi/10.1136/ qshc.2005.015362

13. Yates GR, Hochman RF, Sayles SM, Stockmeier CA. Sentara Norfolk General Hospital: accelerating improvement by focusing on building a culture of safety. Jt Comm J Qual Saf [Internet]. 2004 Oct;30(10):534-42. Available from: http://www. ncbi.nlm.nih.gov/pubmed/15518357

14. Budihardjo A. Pentingnya Safety Culture di Rumah Sakit. Integritas-Jurnal Manaj [Internet]. 2008;10(1):53-70. Available from: http://isjd.pdii. lipi.go.id/admin/jurnal/11085370.pdf

15. Komite Keselamatan Rumah Sakit (KKP-RS) PERSI. Pedoman Pelaporan Insiden Keselamatan Pasien. Jakarta; 2012.

16. Rosyada SD. Gambaran Budaya keselamatan Pasien Pada Perawat Unit Rawat Inap Kelas III
Rumah sakit Umum Daerah Pasar Rebo. Jakarta: Program Studi Kesehatan Masyarakat Fakultas Kedokteran dan Ilmu Kesehatan; 2014.

17. Dwiyanto, A. Penerapan Hospital by Laws Dalam Meningkatkan Patient Rumah Sakit. [Semarang]: Program Pascasarjana UNIKA Soegijapranata; 2007.

18. Zainuddin. Metode Penelitian Hukum. Jakarta: Sinar Grafik; 2010.

19. Agency for Healthcare Research and Quality. Patient Safety Culture Surveys [Internet]. 2004. Available from: http://www.ahrq.gov/qual/ pattientsafetyculture

20. Mukti AG. Strategi Terkini Peningkatan Mutu Pelayanan Kesehatan: Konsep dan Implementasi, Pusat Pengembangan Sistem Pembiayaan dan Manajemen Asuransi/Jaminan Kesehatan, Yogyakarta: Fakultas Kedokteran Universitas Gajah Mada; 2007.

21. Rachmawati E. Model Pengukuran Budaya Patient safety di RS Muhammadiyah-'Aisyiyah Tahun 2011. In: Proseding Penelitian Bidang Ilmu Eksakta. Jakarta: Proseding Penelitian Bidang IImu Eksakta; 2011.

22. Marquis BL, Huston CJ. Leadership Roles and Management Functions In Nursing: Theory and Application. Philidelphia: Lippincott William \& Wilkins; 2006.

23. Robbins SP, Timothy A, Judge. Perilaku Organisasi. $12^{\text {th }}$ Ed. Jakarta: Salemba Empat; 2008.

24. Baker DP, Gustafson S, Beaubien J, Salas E, Barach P. Medical Teamwork and Patient Safety: The Evidence-Based Relation. Publication No.050053 [Internet]. 2005 [cited 2016 Apr 18]. Available from: http://ahrg.gov/qual/medteam

25. Hikmah. Persepsi Staf Mengenai Patient Safety di Instalasi Rawat Darurat RSUP Fatmawati. [Jakarta]: FKM-UI; 2008.

26. Agnew C, Flin R, Mearns K. Patient safety climate and worker safety behaviours in acute hospitals in Scotland. J Safety Res [Internet]. 2013 Jun;45:95-101. Available from: http://www. ncbi.nlm.nih.gov/pubmed/23708480

27. Cahyono JB, Suhardjo B. Membangun Budaya Patient Safety dalam Praktek Kedokteran. Yogyakarta: Kanisius; 2012.

28. National Patient Safety Agency (NPSA). Seven Step to Patient Safety's. An Overview Guide from NHS Staff [Internet]. 2010 [cited 2017 Apr 4]. Available from: www.npsa.nhs.uk/ 